\title{
Interfacial toughening and consequent improvement in fracture toughness of carbon fiber reinforced epoxy resin composites: induced by diblock copolymers
}

\author{
S. H. Deng ${ }^{1}$, X. D. Zhou ${ }^{1 *}$, M. Q. Zhü ${ }^{2}$ C. J. Fan ${ }^{1}$, Q. F. Lin $^{2}$ \\ ${ }^{1}$ State Key Laboratory of Chemical Engineering, East China University of Science and Technology, 130 Meilong Road, \\ 200237 Shanghai, PR China \\ ${ }^{2}$ School of Material Science and Engineering, East China University of Science and Technology, 130 Meilong Road, \\ 200237 Shanghai, PR China
}

Received 6 June 2013; accepted in revised form 24 July 2013

\begin{abstract}
Carbon fibers chemically grafted with hydroxyl-terminated diblock copolymer poly (n-butylacrylate)-b-poly (glycidyl methacrylate) (OH-PnBA-b-PGMA), were used as the reinforcement for epoxy composites. The multi-filament composite specimens were prepared and measured by dynamic mechanical analysis (DMA), to study the interfacial toughness of carbon fiber reinforced epoxy composites with the diblock copolymers. The loss modulus and loss factor peaks of $\beta$-relaxation indicated that composites with diblock copolymers could dissipate more energy at small strain and possess better interfacial toughness, whereas composites without the ductile block PnBA having the worse interfacial toughness. The glass transition temperature and the apparent activation energy calculated from the glass transition showed that the strong interfacial adhesion existed in the composites with diblock copolymers, corresponding with the value of interfacial shear strength. Therefore, a strengthening and toughening interfacial structure in carbon fiber/epoxy composites was achieved by introducing the diblock copolymer OH-PnBA-b-PGMA. The resulting impact toughness, characterized with an Izod impact tester, was better than that of composite without the ductile block PnBA.
\end{abstract}

Keywords: polymer composites, diblock copolymer, interface, fracture toughness, DMA

\section{Introduction}

Carbon fiber reinforced epoxy composites are widely used in many fields, including aerospace, transportation, civil constructions, marine and automobile industries due to their good engineering properties such as high specific strength and stiffness, low density and so on. They have also attracted a longstanding attention [1-5]. However, epoxy resins are inherently brittle and hence have reduced damage tolerance, and consequently the damage tolerance of the epoxy composites. During the past decades, a large number of researches have been aimed at the toughening of epoxy composites. One of the most effective methods is by improving the matrix toughness. For example, ductile thermoplastics and rubbers were used to increase the resin toughness [6] through their plastic deformation. However, this approach may seriously affect modulus and thermal properties of the material for only a modest increase in the toughness. Other techniques include interleaving [7] or toughening with the thermoplastic fibers [8] and carbon nanotubes [9].

The other most effective method is by coating the carbon fibers with a ductile polymeric material before they are incorporated into a matrix. A variety of polymer coatings such as anhydride copolymers

\footnotetext{
${ }^{*}$ Corresponding author, e-mail: xdzhou@ecust.edu.cn

(C) BME-PT
} 
[10], acrylonitrile copolymers [11], polyvinyl alcohol [12] and epoxy coating [13] have been supplied to carbon fibers, and consequently improving the fracture toughness of reinforced composites by modifying the mode of failure and thus the potential energy absorbing capacity. However, these coatings usually provide weak bonding at the interface; thick coatings also result in the reduction of the composite strength and modulus.

Up to date, we synthesized and used the hydroxylterminated diblock copolymer poly (n-butylacrylate)-b-poly (glycidyl methacrylate) (OH-PnBA-bPGMA) as macromolecular coupling agent for applying to the carbon fiber/epoxy composite to yield a strengthening and toughening interface. The Micro-Raman spectroscopy revealed that introducing flexible segment PnBA into the interface can significantly relax the interfacial stress between carbon fibers and epoxy resin. On the other hand, the microbond test showed that the interfacial shear strength of the composites (up to $52.3 \mathrm{MPa}$ ) was also significantly improved due to the grafting of diblock copolymer OH-PnBA-b-PGMA onto the carbon fiber surfaces [14]. However, there is no direct proof to show the improvement of the interfacial toughness and the consequent fracture toughness of composites.

The fracture behavior of polymers under large-scale deformations is of considerable interest for many thermal analysts who are interested in specifying polymers for use in critical load-bearing applications. Brostow and Corneliussen [15] and Chartoff et al. [16] indicated how linear viscoelastic dynamic mechanical analysis (DMA) data can be of benefit as an aid in deciding some practical criteria for selecting what material to use. The relevant relaxation processes are the first secondary relaxation below $T_{\mathrm{g}}$. Hartmann and Lee [17] and Woo et al. [18] had reported a method that by doing a Fourier analysis to obtain the complete frequency spectrum of the impact pulse and comparing this spectrum with the room-temperature frequency spectrum of the loss factor of the secondary transition, the impact resistance was correlated with the secondary transition. They also obtained good agreement between the calculated value and the measured value. More recently, Karger-Kocsis et al. [19] reported that the intensity of the $\beta$-relaxation assigned to conformational changes of the cyclohexylene linkages correlates with the toughness of vinylester/epoxy-based thermosets. All the researches indicated that the impact properties of polymers can be correlated their $\beta$-relaxation.

To our knowledge, there are few reports about the relationship between fracture toughness with $\beta$-relaxation of fiber reinforced polymer composites, due to the complicated failure mechanisms such as matrix fracture, fiber-matrix interface debonding, postdebonding friction, fiber fracture, stress redistribution, fiber pull-out, etc. [12]. However, when small strain is given to composites, the energy absorption and dissipation is mainly dependent on the molecular chain mobility of matrix polymer and interface before failure. In other word, interfacial toughening contributes significantly to material toughness when matrix resin is fixed, and can be correlated with the $\beta$-relaxation of composites. For fiber reinforced polymer composites, we expect that they can not only absorb a large amount of impact energy when failure occurs, but dissipate energy by molecular chain mobility and deformation as encountering relatively small load. Therefore, DMA may be an effective method to analyze the interfacial toughness, although there is a philosophical difficulty in relating the DMA data to the fracture toughness of composites. In this study, to prove that the hydroxyl-terminated diblock copolymer OH-PnBA-b-PGMA can yield a strengthening and toughening interfacial structure in carbon fiber/epoxy composites, the multi-filament composite specimens were prepared and tested by dynamic mechanical analysis (DMA), to thoroughly study the interfacial toughness of carbon fiber reinforced epoxy resin composites. The resulting impact toughness was also characterized with an Izod impact tester.

\section{Experimental section \\ 2.1. Materials}

Carbon fibers (CFs) (T700, approximate diameter is $7 \mu \mathrm{m}, 12000$ single filament in the tow) were purchased from Toray Industries, Inc. Japan. The surface treatments of the CFs were similar to those described in our previous study [14]. The CFs, extracted with acetone (Sinopharm Chemical Reagent Co., Ltd, AR grade, China) and petroleum ether (Shanghai Tianlian Fine Chemical Co., Ltd, AR grade, China) in a Soxhlet apparatus for $24 \mathrm{~h}$ respectively and then dried under vacuum at $60^{\circ} \mathrm{C}$, were denoted as CF0. After extraction, the CFs were oxidized by nitric acid (Yixin Guanghui Addi- 
tives Chemical Co., Ltd, AR grade, China) for $5 \mathrm{~h}$ at $100^{\circ} \mathrm{C}$, denoted as CF-COOH. The as-prepared CF$\mathrm{COOH}$ was immersed in thionyl chloride (Shanghai Lingfeng Chemical Reagent Co., Ltd, AR grade, China) and stirring at $70^{\circ} \mathrm{C}$ for $24 \mathrm{~h}$, and then chemically grafted with the synthesized copolymers $\mathrm{OH}$ PnBA-b-PGMA70 with various polymerization degrees $(0,130$ and 220) of the PnBA blocks, named as CF-PGMA, CF-DI130 and CF-DI220, respectively.

The resin used in this study was the two part E51(618)/T-31 epoxy system, provided by Shanghai Resin Factory Co. Ltd. China.

\subsection{Preparation of the testing samples \\ 2.2.1. Preparation of multi-filament composite specimens}

All the multi-filament composite specimens were prepared as follows: Ten filaments were parallel aligned on a rectangular mould with a size of $30 \times$ $5 \times 0.3 \mathrm{~mm}$ using double-side tape, ensuring that each filament was non-overlapped to avoid the interference between interfaces. Then the resin E51(618) and hardener T-31 were mixed with a mass ratio 10:3, poured into the mould and degassed under full vacuum to enable evaporation of entrapped air bubbles, followed by curing at $60^{\circ} \mathrm{C}$ for $6 \mathrm{~h}$ and subsequent $120^{\circ} \mathrm{C}$ for $5 \mathrm{~h}$ under compressive pressure of $200 \mathrm{kPa}$. The photograph of multi-filament specimen was shown in Figure 1. For all the specimens, the fiber contents were uniform by employing equal amounts of resin and equal numbers of filaments.

It is worth noting that the dimension of specimens must be precisely controlled, especially the thickness, significantly influencing the modulus of materials in DMA test. The specimens will be given up if their thickness does not fall in the range of 300 $350 \mu \mathrm{m}$.

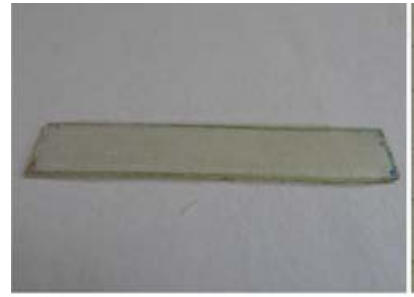

a)

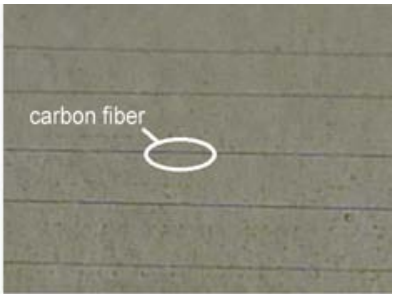

b)
Figure 1. Samples of multi-filament composite specimens for DMA tests (a) photograph of the whole sample; (b) arrangement of single carbon fiber embedded in epoxy resin

\subsubsection{Preparation of notched impact specimens}

The quantitative bundles were first laid in three layers in the mould with the size of $60 \times 10 \times 2.5 \mathrm{~mm}$, followed by pouring the quantitative resin mixture with vacuum degassing. Then the notched impact specimens of the unidirectional composites were obtained after the curing process similar to that described for the preparation of multi-filament specimens. The schematic diagram of the notched impact specimen was shown in Figure 2. The fiber content of all the notched impact specimens was $5 \%$ by weight.

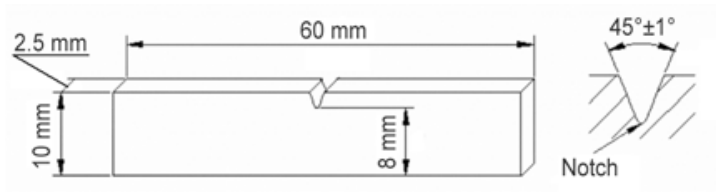

Figure 2. Schematic diagram of the notched impact specimen

\subsection{Instruments and measurements}

Dynamic mechanical thermal analysis (DMA) was performed in film tensile mode with a dynamic mechanical thermal analyzer (DMAQ800, TA Instruments, USA). Using DMA Multi-Frequency-Strain module, the prepared specimens were measured with various oscillation frequencies of $1,5,10,30$ and $50 \mathrm{~Hz}$ and a constant oscillation strain of $0.07 \%$. The testing temperature ranged from -125 to $200^{\circ} \mathrm{C}$ at $2^{\circ} \mathrm{C} / \mathrm{min}$.

Both for the bulk matrix and for the multi-filaments composite specimens, an apparent activation energy $\Delta E$ for the glass transition has been calculated, as reported by other authors [20], using the Arrhenius equation as shown in Equation (1):

$\omega=A \exp \frac{-\Delta E}{R T_{\mathrm{g}}}$

where $\omega$ is the oscillation frequency, $T_{\mathrm{g}}$ is the absolute temperature at the glass transition loss factor peak and $A$ is a frequency factor.

The single fiber pull-out behavior of the multi-filament composites was recorded by the optical microscope (LV100POL, Nikon Corporation, Japan).

The fracture toughness of composites was evaluated using an Izod impact tester (XJU-22J, Chengde Teating Machine Co., Ltd, China) of full scale $4 \mathrm{~J}$ at an impact velocity of $1 \mathrm{~m} / \mathrm{s}$. The notched impact strength was calculated according to ASTM D-256 
at $-50^{\circ} \mathrm{C}$. Each value obtained represented the average of five samples.

Scanning electron microscopy (SEM) was applicable to investigate the surface morphology of the fractured section of the impact specimens. Samples were fixed to a platform with conductive tape, vacuum-dried and sputtered with gold. Images were taken on an S-4800 scanning electron microscopy (Hitachi Company, Japan), operating at $15 \mathrm{kV}$.

\section{Results and discussion}

\subsection{Dynamic mechanical thermal analysis}

\subsubsection{Multi-filament composite specimens}

Considering the appropriate damping for impact would either be longitudinal or some combination of shear and longitudinal, the tensile mode was employed in DMA test. The additional advantage of this mode is benefit of the specimen preparation. It is easy for single filament to be parallel aligned in small dimension specimens. As shown in Figure 1, the multi-filament composite specimens were prepared with the dimension of $30 \times 5 \times 0.3 \mathrm{~mm}$. To ensure all the samples been tested in linear viscoelastic region, the $0.07 \%$ oscillation strain was selected.

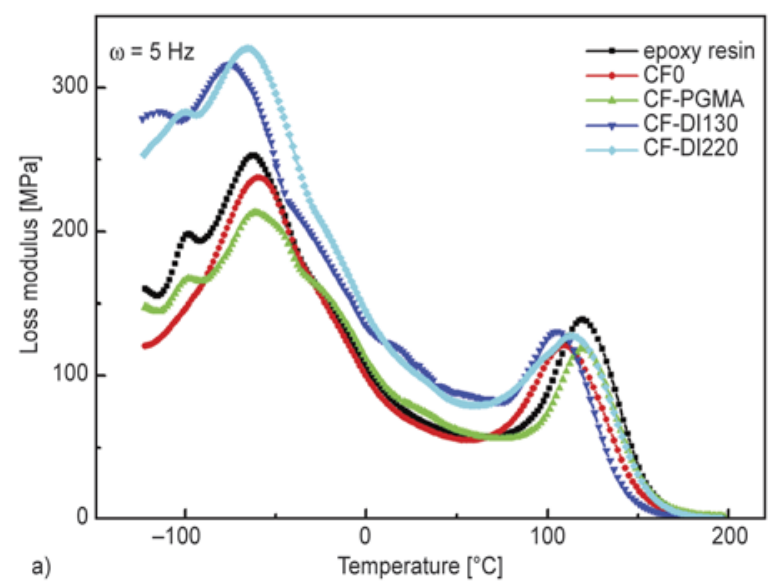

\subsubsection{Loss modulus $E^{\prime \prime}$ of $\beta$-relaxation}

The variation of the dynamic loss modulus $E^{\prime \prime}$ with temperature for the various samples was shown in Figure 3. The values sweeping at 5 and $50 \mathrm{~Hz}$ were selected respectively to be convenient for comparing. Besides the glass transition at the high-temperature end about $140 \sim 150^{\circ} \mathrm{C}$, one secondary transition was found at $-60 \sim-50^{\circ} \mathrm{C}$. This phenomenon had been widely reported [21, 22]. The peak value of loss modulus and $S_{\beta-\mathrm{L}}$, the area under the loss modulus curve at 5 and $50 \mathrm{~Hz}$, were listed in Table 1. For epoxy/amine networks, most authors associated the $\beta$-relaxation with the motion contributions of diphenylpropane groups and glyceryl units [21-23]. Comparing the loss modulus of the bulk matrix and the multi-filament composites at the secondary transition, the peak value of the neat epoxy resin was lower than that of CF-DI220 and CF-DI130 composites, whereas it higher than that of $\mathrm{CF} 0$ and CF-GMA composites, both sweeping at 5 and $50 \mathrm{~Hz}$. The loss modulus is the viscous component of complex modulus and is related to the sample's ability to dissipate mechanical energy as heat through the molecular motion per cycle of sinusoidal deformation, when different systems are compared at the

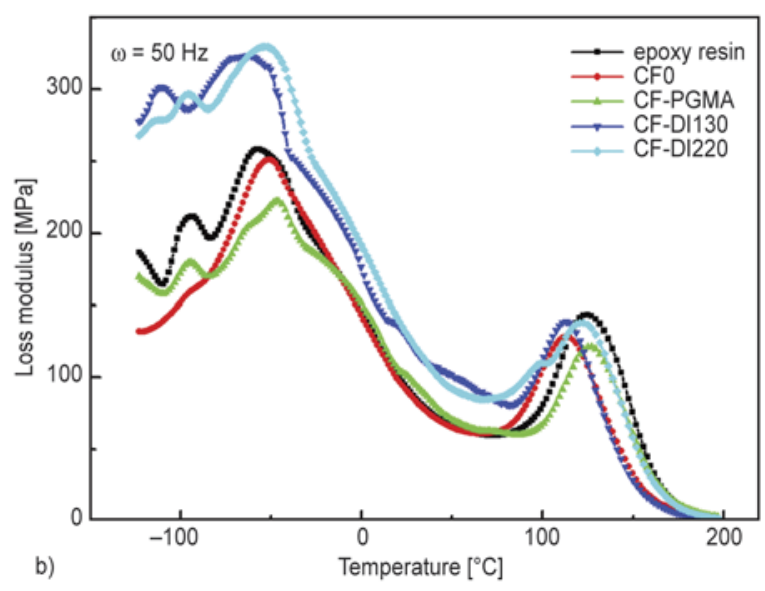

Figure 3. Loss modulus of various samples as a function of temperature, sweeping at (a) $5 \mathrm{~Hz}$ and (b) $50 \mathrm{~Hz}$, respectively

Table 1. Data about $\beta$-relaxation of carbon fiber/epoxy resin composites

\begin{tabular}{|c|c|c|c|c|c|c|}
\hline \multirow[t]{2}{*}{ Sample } & \multicolumn{3}{|c|}{$5 \mathrm{~Hz}$} & \multicolumn{3}{|c|}{$50 \mathrm{~Hz}$} \\
\hline & $\begin{array}{c}\text { Loss modulus } \\
\text { [MPa] }\end{array}$ & $S_{\beta-L \cdot 10^{-3}}$ & $\mathbf{S}_{\boldsymbol{\beta}-\delta}$ & $\begin{array}{c}\text { Loss modulus } \\
\text { [MPa] }\end{array}$ & $S_{\beta-L \cdot 10^{-3}}$ & $\mathbf{S}_{\boldsymbol{\beta}-\delta}$ \\
\hline Epoxy & 252.7 & 27.6 & 9.2 & 258.0 & 31.5 & 10.3 \\
\hline CF0 & 237.3 & 25.2 & 7.5 & 251.3 & 29.0 & 8.6 \\
\hline CF-PGMA & 213.2 & 25.7 & 8.9 & 222.3 & 29.2 & 9.9 \\
\hline CF-DI130 & 316.8 & 31.2 & 12.9 & 323.1 & 41.5 & 13.9 \\
\hline CF-DI220 & 327.4 & 38.5 & 13.1 & 328.9 & 43.1 & 14.3 \\
\hline
\end{tabular}

$S_{\beta-\mathrm{L}}$ is area under the loss modulus curve, $S_{\beta-\delta}$ is area under the $\tan \delta$ curve. 
same strain amplitude. It is most sensitive to the molecular motions. The dissipation from the mechanical energy into thermal energy per cycle is described in Equation (2) [18]:

$$
\begin{aligned}
& \Delta W(\omega)=\int_{"}^{2 \pi / \omega} \sigma(\omega) \cdot \varepsilon(\omega) \mathrm{d} t \\
& =\omega \cdot \sigma_{0} \cdot \varepsilon_{0} \int_{0}^{2 \pi / \omega}\left[\cos \omega t \cdot \sin \omega t \cdot \cos \delta+\sin ^{2} \omega t \cdot \sin \delta\right] \mathrm{d} t \\
& =\pi \cdot \varepsilon_{0}^{2}(\omega) \cdot E^{\prime \prime}(\omega)
\end{aligned}
$$

where $\sigma(\omega)$ is the stress at frequency $\omega, \varepsilon(\omega)$ is the resulting strain at $\omega$ with amplitude $\varepsilon_{0}, \delta$ is the phase angle between stress and the strain, $E^{\prime \prime}(\omega)$ is the loss modulus at $\omega$.

It was found that $S_{\beta-\mathrm{L}}$, area under the loss modulus curve, also had the similar trend as that of loss modulus: CF-DI220 $>$ CF-DI130 $>$ epoxy resin $>$ CF0 $\approx$ CF-GMA.

Thus, it implied that the energy dissipation capacity of the neat epoxy resin was lower than that of CFDI220 and CF-DI130 composites, and higher than that of CF0 and CF-GMA composites. At small strain $(0.07 \%)$, the multi-filament composites have no detectable matrix fracture and fiber pull-out, the variation of toughness is mainly contributed by the interfacial toughness as the resin matrix is fixed. We have known that the glass transition of PnBA block in diblock copolymer occurs at about $-50^{\circ} \mathrm{C}$. It can increase the frictional shear work due to its high viscosity and the plastic deformation at the interface, and act as a stress relief medium which reduces compressive stresses caused by matrix shrinkage during curing and as a crack inhibitor [24]. In our previous study, Micro-Raman spectroscopy has also revealed the interfacial stress can significantly be relaxed owing to introducing the flexible segment PnBA [14]. Thus, the CF-DI220 and CF-DI130 composites possess better energy dissipation capacity and toughness than the neat epoxy matrix. It was noted that CF0 multi-filament composite showed lower energy dissipation than the neat epoxy matrix. Commonly, weak interfacial adhesion provides slight limit to the neighboring chain motion; whereas good interfacial adhesion seriously restricts the movement of the chain segments, resulting in the worst interfacial toughness of CF-GMA composite.

\subsubsection{Loss factor $\tan \delta$ of $\beta$-relaxation}

The loss factor $\tan \delta$ is the ratio of loss modulus to storage modulus, and represents the mechanical damping or the internal friction in a viscoelastic system. Compared with loss modulus, the loss factor eliminates the effect of sample's geometrical shapes. The variation of loss factor tan $\delta$ with temperature for various samples was shown in Figure 4, and $S_{\beta-\delta}$, the area under the $\tan \delta$ curve was also shown in Table 1.

As can be seen from Table 1 and Figure $4, S_{\beta-\delta}$ ranged as: CF-DI220 > CF-DI130 > epoxy resin $>$ CF-GMA $>\mathrm{CF} 0$, both sweeping at 5 and $50 \mathrm{~Hz}$. The similar trend with that of loss modulus, composites with diblock copolymer possessing the best interfacial toughness and composites without the ductile block PnBA having the worse interfacial toughness, was very significant. This is not in accordance with the principle that a composite with a poor matrix/ fiber load transfer tends to dissipate more energy than one with good interfacial interaction [25]. As reported in our recent study, the micro-composite with diblock copolymer coupling agent had strong
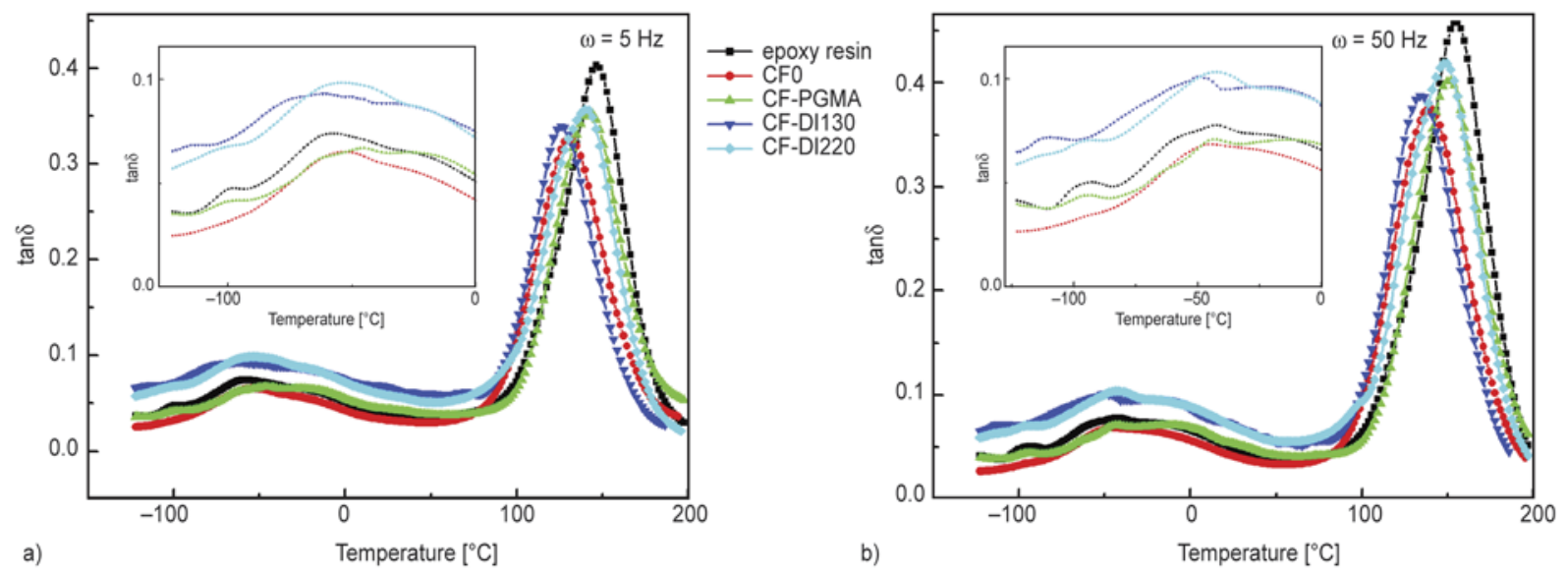

Figure 4. Loss factor of various samples as a function of temperature, sweeping at (a) $5 \mathrm{~Hz}$ and (b) $50 \mathrm{~Hz}$, respectively 


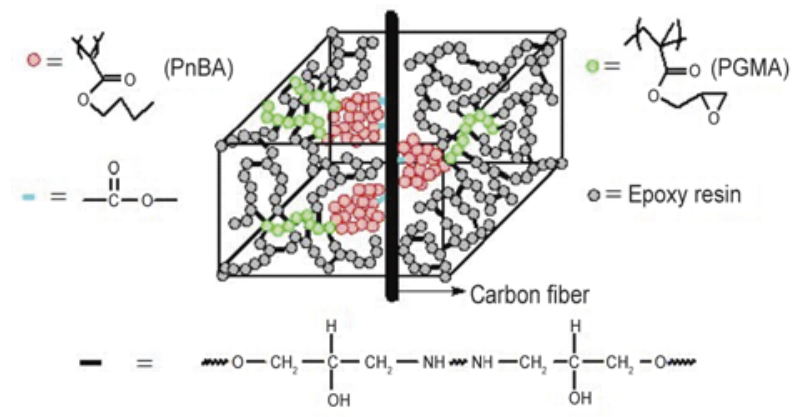

Figure 5. Schematic illustration on the interactions of grafted diblock copolymer at the interface between $\mathrm{CF}$ and epoxy resin

interfacial shear strength of $49.0 \mathrm{MPa}$ (CF-DI220), while the micro-composite with PGMA and CF0 had only interfacial shear strength of 40.2 and 29.8 MPa, respectively [14].

We have reported in our other paper that, the ductile block PnBA will act as the ductile interlayer collapsing on fiber surface due to its low $T_{\mathrm{g}}$ and poor compatibility with the PGMA block and the epoxy resin [26], which is illustrated in Figure 5. It is well acceptable that the ductile PnBA interlayer with high viscosity will increase frictional shear stress at interface, and the movement of PnBA chain segments at interface also improves the plastic deformation of the interface region.

\subsection{4. $\alpha$-relaxation}

Table 2 showed that the glass transition temperature, from the loss factor for bulk resin and composites at various testing frequencies. It is evident from the loss factor curves that all the multi-filament composites show a relaxation peak at temperatures lower than that obtained from bulk resin. Ratna [27] reported that the $T_{\mathrm{g}}$ for GFRP epoxy composite was $190^{\circ} \mathrm{C}$ whereas for unreinforced cured epoxy it was $217^{\circ} \mathrm{C}$. Ghosh et al. [28] reported similar effects in the case of jute fiber reinforced composites. They explained that the organosilane coating used for commercial fibers, with unreactive organic groups led to an interface with many unrestrained or free

Table 2. Data about $\alpha$-relaxation of carbon fiber/epoxy resin composites

\begin{tabular}{|l|c|c|c|}
\hline \multicolumn{1}{|c|}{ Sample } & $\begin{array}{c}\mathbf{T}_{\mathbf{g}} \\
{\left[{ }^{\circ} \mathbf{C}, \mathbf{5} \mathbf{~ H z}\right]}\end{array}$ & $\begin{array}{c}\mathbf{T}_{\mathbf{g}} \\
{\left[{ }^{\circ} \mathbf{C}, \mathbf{5 0} \mathbf{~ H z}\right]}\end{array}$ & $\begin{array}{c}\text { Activation energy, } \\
\Delta \mathbf{E}\left[\mathbf{k J} \cdot \mathbf{m o l}^{-\mathbf{1}}\right]\end{array}$ \\
\hline Epoxy & 146.4 & 155.7 & 325.1 \\
\hline CF0 & 136.8 & 144.4 & 365.9 \\
\hline CF-PGMA & 142.6 & 151.9 & 402.0 \\
\hline CF-DI130 & 142.2 & 149.8 & 427.9 \\
\hline CF-DI220 & 141.3 & 148.9 & 421.3 \\
\hline
\end{tabular}

end groups which resulted in reduction in the crosslink density of the polymer network in the interface region, and thereby caused a reduction in relaxation temperature [29]. In our experiments, we used the macromolecular coupling agents synthesized by ourselves, but not the commercial organosilane coating, the similar effects were also obtained. It was considered that the thickness of the prepared multi-filament specimens is only about $300 \mu \mathrm{m}$, the parallel arrangement of CF with and without coating slightly reduced the cross-link density and integrality of the polymer network in the interface region. Furthermore, for the CF0 composite, the presence of uncoated fibers can affect the initial stoichiometry of the epoxy-amine network due to the higher affinity of the carbon surface for one of the monomers. The generation of a non-stoichiometric interphase is possibly the reason of the decrease of $T_{\mathrm{g}}$ [29]. For the CF-GMA, CF-DI130 and CF-DI220 composites, some epoxy groups in PGMA block react with amine hardener during the curing process; the others unreacted are free or unrestrained and have a plasticization effect on the zone next to the interface, explaining the decrease in $T_{\mathrm{g}}$ of the composites.

Obviously, the CF0 composite desized the commercial coating on carbon fibers had the lowest $T_{\mathrm{g}}$. Usually, the good interfacial adhesion will restrict the chain segment movement, resulting in an increase in glass transition temperature. Thereby, the $T_{\mathrm{g}}$ of composites with macromolecular coupling agents was higher than that of $\mathrm{CF} 0$ composite. However, the ductile interlayer still affected the $T_{\mathrm{g}}$. This is confirmed by the descending order of $T_{\mathrm{g}}$ value for CFPGMA, CF-DI130 and CF-DI220 composites, in which the polymerization degree of PnBA block is 0,130 and 220, respectively.

According to Equation (1), by plotting the logarithm of the frequency vs. the reciprocal absolute temperature corresponding to the $\tan \delta$ peak, the apparent activation energy for the glass transition can be calculated from the slope of the regression line. Figure 6 showed this relationship, and the calculated values for the apparent activation energies of epoxy matrix and multi-filament composites were listed in Table 2. As can be seen, the relaxation of the epoxy matrix required the least energy compared with all the multi-filament composites. The desized fibers micro-composites $\mathrm{CF} 0$ had a bit higher value, implying that the molecular motion was only 
slightly restricted by the reinforcing fibers. This is due to the weak interfacial adhesion between CF0

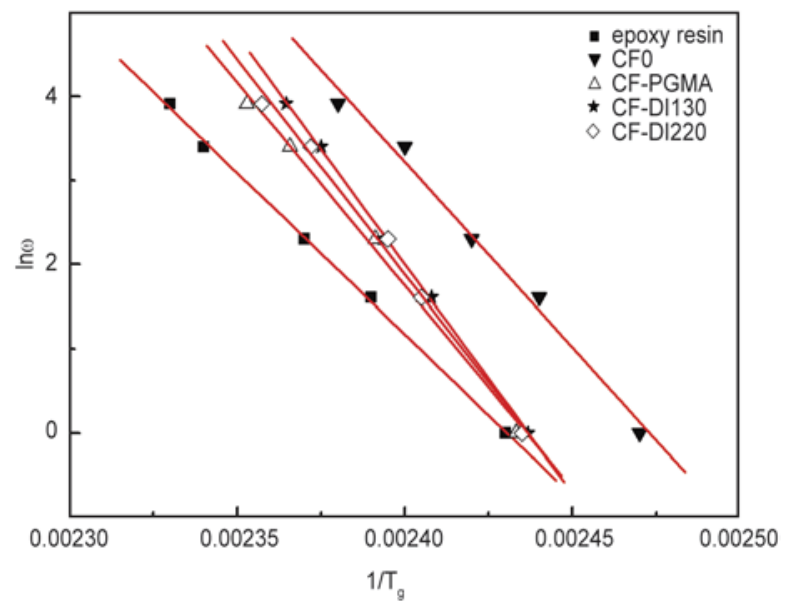

Figure 6. The relationship curves between $1 / T_{\mathrm{g}}$ and $\ln \omega$ in pure epoxy resin and carbon fibers with various surface modification reinforced epoxy resin composites

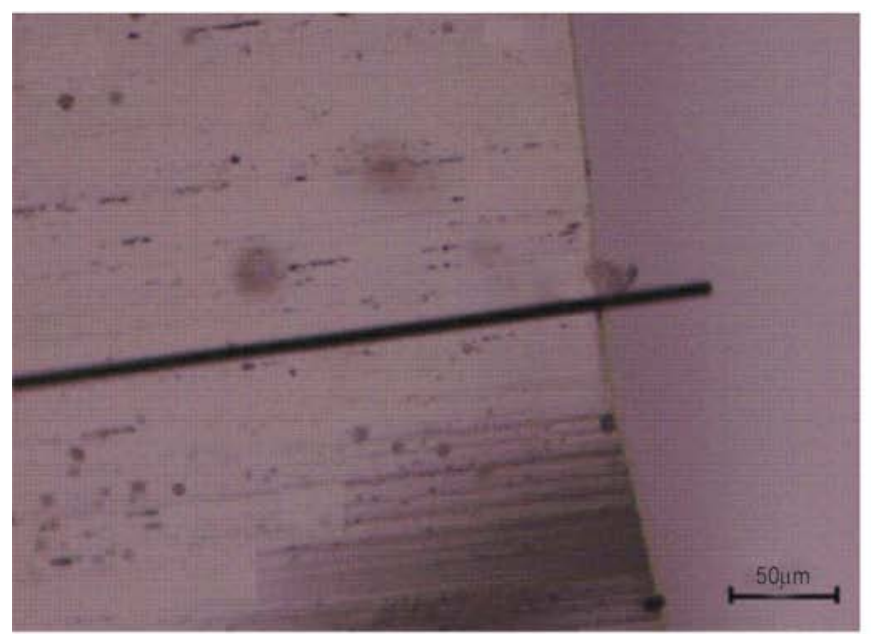

a)

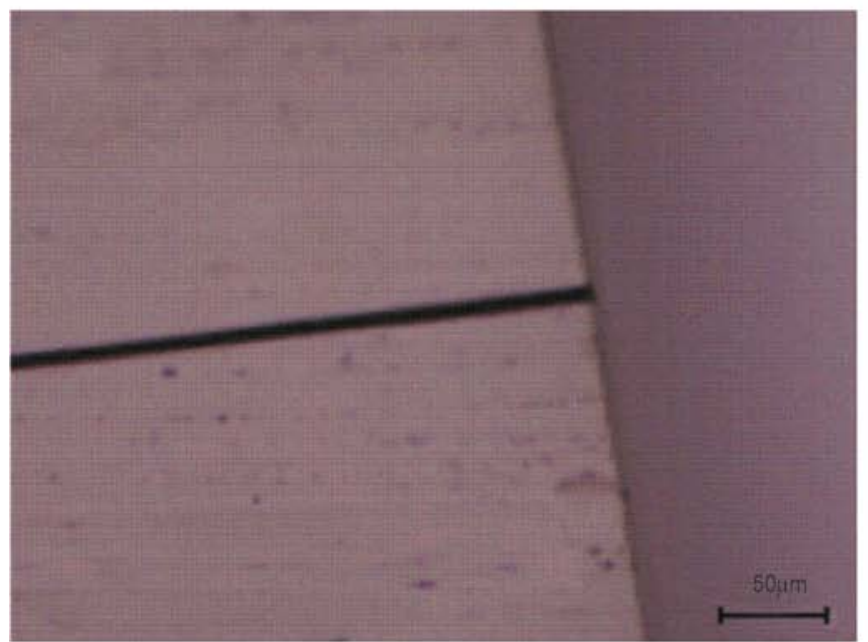

c) and epoxy matrix. The relaxation of the epoxy resin in composites with dibock copolymer required the most energy, relating to the best interfacial adhesion. It could be clearly seen that there was a very good agreement between the activation energy and the interfacial adhesion, indicating the strengthening and toughening interfacial structure in carbon fiber reinforced epoxy resin composites induced by diblock copolymer OH-PnBA-b-PGMA.

\subsection{Single fiber pull-out}

Many researchers have proved the fiber pull-out work $\left(R_{\mathrm{po}}\right)$ to be a predominant component of the fracture toughness (more than $90 \%$ ) of carbon fiber reinforced plastics [12, 30]. Kim and Mai employed Equation (3) to estimate the fiber pull-out work:

$R_{\mathrm{po}}=\frac{V_{\mathrm{f}} \cdot \sigma_{\mathrm{f}} \cdot l_{\mathrm{c}}}{12}=\frac{V_{\mathrm{f}} \cdot \sigma_{\mathrm{f}} \cdot \bar{l}_{\mathrm{po}}}{3}$

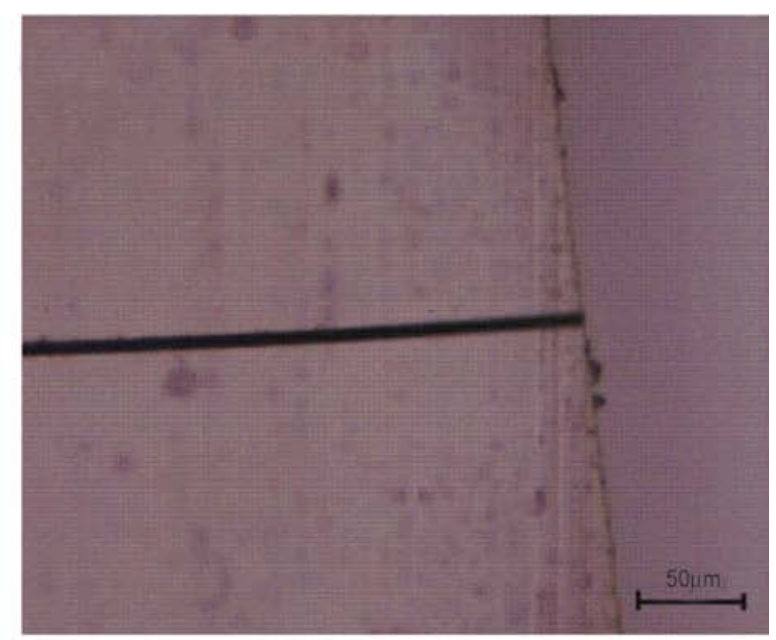

b)

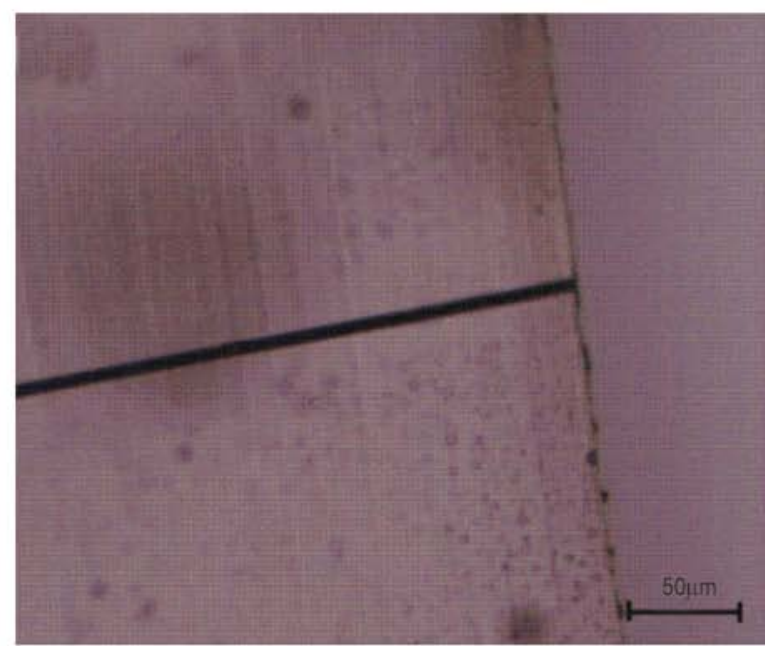

Figure 7. Optical micrographs of the multi-filament composites after fracture under the dynamic load of $50 \mathrm{~Hz}$. (a) CF0/epoxy resin; (b) CF-COOH/epoxy resin; (c) CF-PGMA/epoxy resin; (d) CF-DI220/epoxy resin 
where $V_{\mathrm{f}}$ is the volume fraction of fibers, $\sigma_{\mathrm{f}}$ is the tensile strength of carbon fibres, and $\bar{l}_{\mathrm{po}}$ is the average fiber pull-out length.

In our experiments, after specimens fracture under the dynamic load of $50 \mathrm{~Hz}$, the fiber pull-out length of the multi-filament composites is easy to measure when employing optical microscope or SEM. As can be seen in Figure 7, the average fiber pull-out length and number of CF0 composite was significantly higher than all the other samples. CF-GMA, CF-DI130 and CF-DI220 composites were seldom observed the phenomenon of fiber pull-out, according with Beaumont's and Anstice [31] opinion that the debonding of single fibers seldom occurs because the debond stress is greater than the fiber strength for carbon-epoxy composites with strong interfacial bond strength and high-stiffness fibers. Therefore, for the composites with diblock copolymer, the energy dissipation cannot be improved through the interfacial debonding and fiber pull-out.

\subsection{Impact fracture toughness}

Figure 8 showed the notched impact strength of carbon fibers reinforced epoxy composites with various surface modifications. It can be found that the impact strength of CF0 composite was as high as $19.05 \pm 2.10 \mathrm{~kJ} / \mathrm{m}^{2}$. It is due to the fact that the weak interfacial bonding between CF0 and epoxy resin allows more interfacial debonding and fiber pullout during the whole fracture process, giving large contributions to the fracture toughness of the composite. Compared to $\mathrm{CF} 0$ composite, much lower impact strength was observed in $\mathrm{CF}-\mathrm{COOH}$ and CF-PGMA composites, only $4.50 \pm 0.52$ and $3.80 \pm 1.21 \mathrm{~kJ} / \mathrm{m}^{2}$, respectively. This is because that

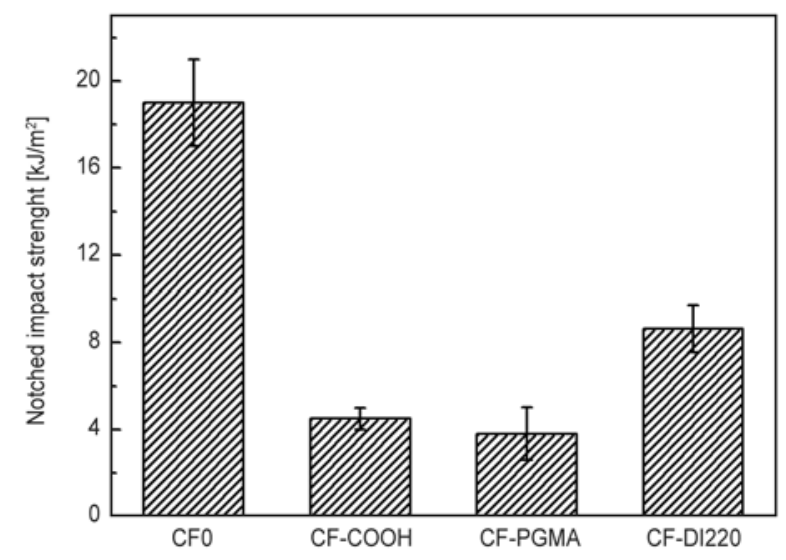

Figure 8. The notched impact strength of carbon fibers with various surface modification reinforced epoxy resin composites the increase of the oxygen-containing functional groups on $\mathrm{CF}-\mathrm{COOH}$ surface and the strong interaction between the grafted homopolymers PGMA and epoxy resin greatly improved the interfacial adhesion of the systems. In the case of strong bonding, the interfacial debonding during the fracture process is so difficult that the advancing crack propagates through the fibers, resulting in the low energy dissipation. As a consequence, the fracture toughness significantly reduced.

However, with the introducing of PnBA blocks, the impact fracture toughness of the composite was slightly increased due to the low grafting density of diblock copolymer. As we known, the strong bonding between carbon fiber and epoxy resin is essential for efficient stress transfer and thus to achieve high strength in CF-DI220 composite, suggesting that the dominant source of the fracture toughness in the system is not attributed to the said toughening mechanisms of interfacial debonding and fiber fullout, which was also indicated by the result of single fiber pull-out. It can be explained as follows: first, the flexible interlayer can bear larger imposed deformation and relax the stress concentration at interface, which delays the occurrence of interfacial slippage and the interfacial debonding, and effectively enhance the number of starting points of the material damage; second, the flexible interlayer can act as a crack arrester to prevent the crack propagation through the fibers and thus prolong the crack propagation path; finally, the composite can overall deform more largely before failure. All of these delay the material damage and increase the energy absorption capacity. Therefore, the notched impact strength of CF-DI220/epoxy resin composite was increased to $9.21 \pm 1.42 \mathrm{~kJ} / \mathrm{m}^{2}$.

Figure 9 demonstrated the fracture morphology in different carbon fiber reinforced epoxy resin composites. For CF0 composite, as seen in Figure 9a, CF was obviously pulled out with a smooth surface from the epoxy resin, and a number of holes were residual, proving that the main failure mechanism of the CF0 composite was the fiber debonding and pull-out. While with an increase in the interfacial adhesion, the brittle fracture occurred in CF-PGMA composite as illustrated in Figure 9b. As for CFDI220 composite (Figure 9c), the fiber debonding phenomenon was also seldom observed due to the strong interfacial bonding. Nevertheless, the fracture model was changed with introducing the flexi- 


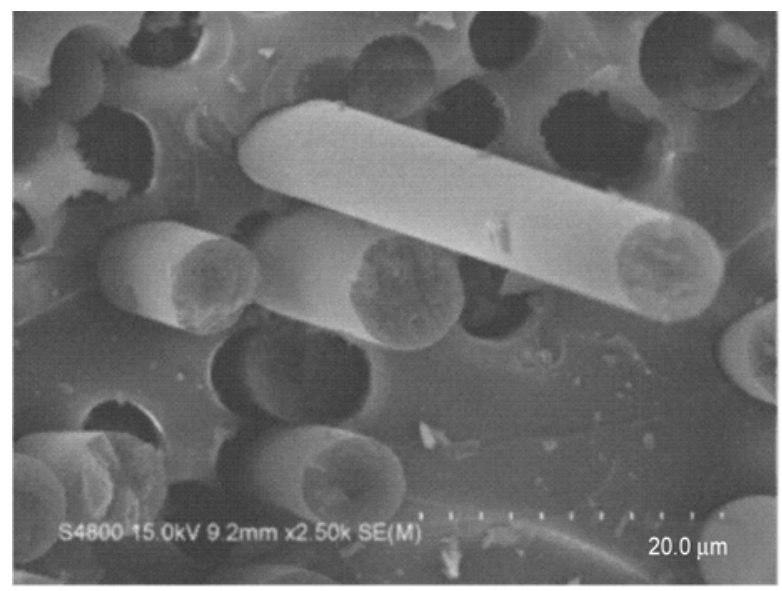

a)

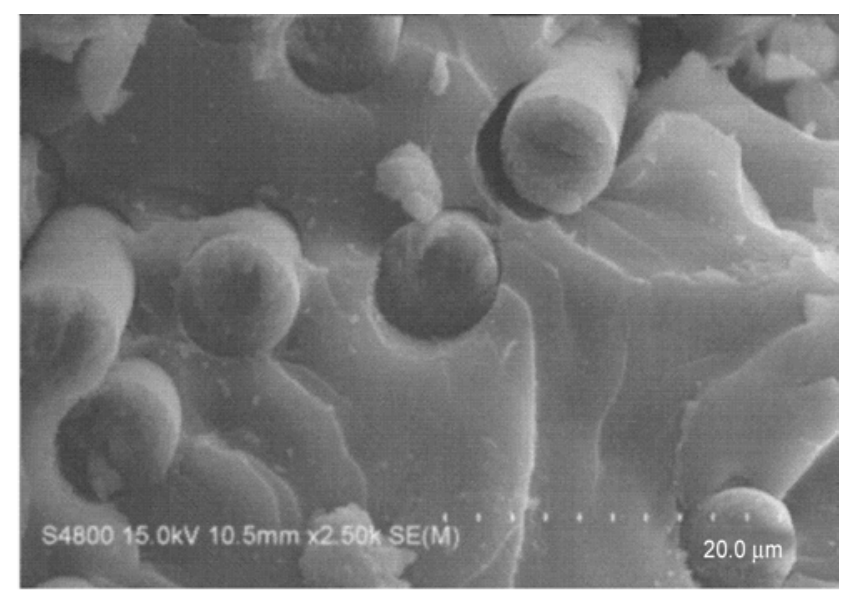

b)

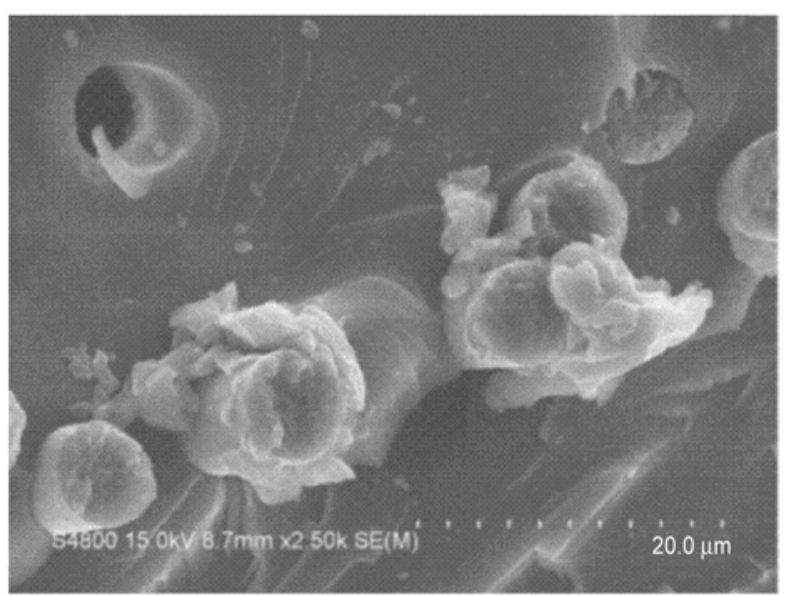

c)

Figure 9. SEM photographs of impact fracture surfaces for (a) CF0/epoxy resin; (b) CF-PGMA/epoxy resin; and (c) CFDI220/epoxy resin composites

ble block PnBA, where amount of the residual resin adhered around the fractured fibers.

\section{Conclusions}

Based on our previous study, the influence of the grafted diblock copolymer OH-PnBA-b-PGMA, which could effectively improve the interfacial adhesion between carbon fiber and epoxy resin, on the interfacial toughness and consequent fracture toughness of the composites was studied by DMA and Izod impact test in this study.

The loss modulus and loss factor peaks of $\beta$-relaxation in DMA spectra showed that the composites with diblock copolymers could dissipate more energy at small strain and possess better interfacial toughness, whereas composites without the ductile block PnBA having the worse interfacial toughness. The glass transition temperature and the apparent activation energy calculated from the glass transition displayed that the strong interfacial adhesion existed in the composites with diblock copolymers, corresponding with the value of the interfacial shear strength.

The ductile block PnBA can bear larger imposed deformation and relax the stress concentration at interface, which delays the occurrence of interfacial slippage and the interfacial debonding, increasing the energy absorption capability and thus improving the impact fracture toughness of the composites.

Therefore, it can be concluded that a strengthening and toughening interfacial structure in carbon fiber reinforced epoxy resin composite was successfully achieved by introducing the diblock copolymer OH-PnBA-b-PGMA.

\section{Acknowledgements}

The authors sincerely acknowledge the support of NSFC 51073055 and the Fundamental Research Funds for the Central Universities. 


\section{References}

[1] Li M., Gu Y., Liu Y., Li Y., Zhang Z.: Interfacial improvement of carbon fiber/epoxy composites using a simple process for depositing commercially functionalized carbon nanotubes on the fibers. Carbon, 52, 109 121 (2013).

DOI: $10.1016 /$ j.carbon.2012.09.011

[2] Ma K., Chen P., Wang P., Cui G., Xu X.: A study of the effect of oxygen plasma treatment on the interfacial properties of carbon fiber/epoxy composites. Journal of Applied Polymer Science, 118, 1606-1614 (2010). DOI: 10.1002/app.32549

[3] Wang C., He X., Tong L., Peng Q., Wang R., Li Y., Li Y.: Theoretical prediction and experimental verification of pulling carbon nanotubes from carbon fiber prepared by chemical grafting method. Composites Part A: Applied Science and Manufacturing, 50, 1-10 (2013). DOI: 10.1016/j.compositesa.2013.03.008

[4] Zhao F., Huang Y., Liu L., Bai Y., Xu L.: Formation of a carbon fiber/polyhedral oligomeric silsesquioxane/ carbon nanotube hybrid reinforcement and its effect on the interfacial properties of carbon fiber/epoxy composites. Carbon, 49, 2624-2632 (2011). DOI: $10.1016 /$ j.carbon.2011.02.026

[5] Shams S. S., El-Hajjar R. F.: Overlay patch repair of scratch damage in carbon fiber/epoxy laminated composites. Composites Part A: Applied Science and Manufacturing, 49, 148-156 (2013).

DOI: 10.1016/j.compositesa.2013.03.005

[6] Pearson R. A., Yee A. F.: Toughening mechanisms in elastomer-modified epoxies. Journal of Materials Science, 24, 2571-2580 (1989).

DOI: $10.1007 / \mathrm{BF} 01174528$

[7] Kuwata M., Hogg P. J.: Interlaminar toughness of interleaved CFRP using non-woven veils: Part 1. ModeI testing. Composites Part A: Applied Science and Manufacturing, 42, 1551-1559 (2011).

DOI: $10.1016 /$ j.compositesa.2011.07.016

[8] Wong D. W. Y., Lin L., MaGrail P. T., Peijs T., Hogg P. J.: Improved fracture toughness of carbon fibre/epoxy composite laminates using dissolvable thermoplastic fibres. Composites Part A: Applied Science and Manufacturing, 41, 759-767 (2010).

DOI: $10.1016 /$ j.compositesa.2010.02.008

[9] Gkikas G., Barkoula N-M., Paipetis A. S.: Effect of dispersion conditions on the thermo-mechanical and toughness properties of multi walled carbon nanotubes-reinforced epoxy. Composites Part B: Engineering, 43, 2697-2705 (2012).

DOI: 10.1016/j.compositesb.2012.01.070

[10] Subramanian R. V., Crasto A. S.: Electrodeposition of a polymer interphase in carbon-fiber composites. Polymer Composites, 7, 201-218 (1986).

DOI: $\underline{10.1002 / p c .750070403}$
[11] Chang J., Bell J. P., Shkolnik S.: Electro-copolymerization of acrylonitrile and methyl acrylate onto graphite fibers. Journal of Applied Polymer Science, 34, 21052124 (1987).

DOI: $10.1002 / a p p .1987 .070340605$

[12] Kim J. K., Mai Y-W.: Effects of interfacial coating and temperature on the fracture behaviours of unidirectional Kevlar and carbon fibre reinforced epoxy resin composites. Journal of Materials Science, 26, 47024720 (1991).

DOI: $10.1007 / \mathrm{BF} 00612409$

[13] Guo H., Huang Y., Liu L., Shi X.: Effect of epoxy coatings on carbon fibers during manufacture of carbon fiber reinforced resin matrix composites. Materials and Design, 31, 1186-1190 (2010).

DOI: $10.1016 / \mathrm{j}$. matdes.2009.09.034

[14] Deng S., Zhou X., Fan C., Lin Q., Zhou X.: Release of interfacial thermal stress and accompanying improvement of interfacial adhesion in carbon fiber reinforced epoxy resin composites: Induced by diblock copolymers. Composites Part A: Applied Science and Manufacturing, 43, 990-996 (2012).

DOI: 10.1016/j.compositesa.2012.01.004

[15] Brostow W., Corneliussen R. D.: Failure of plastics. Hanser, New York (1986).

[16] Chartoff R. P., Menczel J. D., Dillman S. H.: Dynamic mechanical analysis (DMA). in 'Thermal analysis of polymers, fundamentals and applications' (eds.: Menczel J. D., Bruce P. R.) Wiley, New Jersey, 428432 (2009).

DOI: $10.1002 / 9780470423837 . c h 5$

[17] Hartmann B., Lee G. F.: Impact resistance and secondary transitions. Journal of Applied Polymer Science, 23, 3639-3650 (1979). DOI: $10.1002 /$ app.1979.070231219

[18] Woo L., Westphal S., Ling M. T. K.: Dynamic mechanical analysis and its relationship to impact transition. Polymer Engineering and Science, 34, 420-427 (1994). DOI: $10.1002 /$ pen.760340507

[19] Karger-Kocsis J., Gryshchuk O., Jost N.: Toughness response of vinylester/epoxy-based thermosets of interpenetrating network structure as a function of the epoxy resin formulation: Effects of the cyclohexylene linkage. Journal of Applied Polymer Science, 88, 21242131 (2003). DOI: $10.1002 /$ app.11946

[20] Pothan L. A., Oommen Z., Thomas S.: Dynamic mechanical analysis of banana fiber reinforced polyester composites. Composites Science and Technology, 63, 283-293 (2003). DOI: $10.1016 / \mathrm{S} 0266-3538(02) 00254-3$

[21] Lauprêtre F., Eustache R-P., Monnerie L.: High-resolution solid-state ${ }^{13} \mathrm{C}$ nuclear magnetic resonance investigation of local motions in model epoxy resins. Polymer, 36, 267-274 (1995).

DOI: $10.1016 / 0032-3861(95) 91313-\mathrm{V}$ 
[22] Garcia F. G., Soares B. G., Pita V. J. R. R., Sánchez R., Rieumont J.: Mechanical properties of epoxy networks based on DGEBA and aliphatic amines. Journal of Applied Polymer Science, 106, 2047-2055 (2007). DOI: $10.1002 /$ app.24895

[23] Delatycki O., Shaw J. C., Williams J. G.: Viscoelastic properties of epoxy-diamine networks. Journal of Polymer Science Part A2, 7, 753-762 (1969).

DOI: 10.1002/pol.1969.160070501

[24] Kim J. K., Mai Y. W.: High strength, high fracture toughness fibre composites with interface control - A review. Composites Science and Technology, 41, 333378 (1991).

DOI: $10.1016 / 0266-3538(91) 90072-W$

[25] Dong S., Gauvin R.: Application of dynamic mechanical analysis for the study of the interfacial region in carbon fiber/epoxy composite materials. Polymer Composites, 14, 414-420 (1993). DOI: $10.1002 /$ pc. 750140508

[26] Deng S., Ma W., Zhou X., Fan C.: Maintenance of highly interfacial shear strength by diblock copolymer between carbon fiber and epoxy resin in hostile environment. Composite Interfaces, 19, 499-509 (2012). DOI: $\underline{10.1080 / 15685543.2012 .761810}$
[27] Ratna D.: Toughened FRP composites reinforced with glass and carbon fiber. Composites Part A: Applied Science and Manufacturing, 39, 462-469 (2008).

DOI: 10.1016/j.compositesa.2007.12.005

[28] Ghosh P., Bose N. R., Mitra B. C., Das S.: Dynamic mechanical analysis of FRP composites based on different fiber reinforcements and epoxy resin as the matrix material. Journal of Applied Polymer Science, 64, 2467-2472 (1997).

DOI: 10.1002/(SICI)1097-4628(19970620)64:12<2467 :AID-APP21>3.0.CO;2-X

[29] Gupta V. B., Drzal L. T., Lee C. Y-C., Rich M. J.: The effects of stoichiometry and structure on the dynamic torsional properties of a cured epoxy resin system. Journal of Macromolecular Science Part B: Physics, 23, 435-438 (1984).

DOI: $10.1080 / 00222348408219470$

[30] Kirk J. N., Munro M., Beaumont P. W. R.: The fracture energy of hybrid carbon and glass fibre composites. Journal of Materials Science, 13, 2197-2204 (1978). DOI: $10.1007 / \mathrm{BF} 00541674$

[31] Beaumont P. W. R., Anstice P. D.: A failure analysis of the micromechanisms of fracture of carbon fibre and glass fibre composites in monotonic loading. Journal of Materials Science, 15, 2619-2635 (1980).

DOI: $10.1007 / \mathrm{BF} 00550768$ 